$\S=-1$

\title{
Fiber Surface Modification; Characterization of Rattan Fiber Reinforced Composite
}

\author{
Flora Elvistia Firdaus ${ }^{1 *}$, M. Dachyar ${ }^{2}$ \\ ${ }^{1}$ Department of Chemical Engineering, Jayabaya University, Jl. Pulomas Kav 23 Jakarta- 13210, Indonesia \\ Department of Industrial Engineering,Universitas Indonesia - Depok, Indonesia \\ *Corresponding authorE-mail: flora_elvistia@yahoo.com,mdachyar@yahoo.com
}

\begin{abstract}
Increasing the awareness of global warming and the depletion of petroleum resources had made many researchers focuses on using natural materials such as rattan. Its an edible fibers are prepared to reinforce matrix yielding composite products within the aid of epoxy based resin and hardener which also perform as catalyst. The fibres are previously conducted an alkali treatment, this was considered to enhance the cohessiveness of fibers to matrix. Silane and dimethylethanolamine (DMEA) as an adhesives booster is respectively added to the composite formula. The specific purpose of this research is to know the influence of addition of Silane and DMEA to the final properties of composite; flexural, tensile strength, elongation at break, hardness, and thermal. From the test results it is found that Silane keeps the matrix amorphous, while the addition of DMEA formed crystalline polymer. The ultimate property of the composites are found also depends on fiber woven pattern.
\end{abstract}

Keywords: Composite, Woven bamboo fiber, Adhesives booster

\section{Introduction}

Polymer composites can be used for many applications, are assessed as environmentally correct material owing to its biodegradation and renewable characteristics, in addition to cheaper production costs when compared to synthetic materials, it has good physicochemical properties. The advantage of using natural fibers if as composite boosters compared to synthetic fibers (kevlar, aramid, carbon) is better mechanical properties, can reduce tool wear, faster energy recovery, and easy to decompose. Natural fibers can affect the mechanical properties of the eco-matrix [1] Research on plant fiber composites generally focuses on structural fibrous structures and composite matrix, regardless of porosity [2]. This step is justified for synthetic fibers, though still maintaining and controlling porosity of less than $2 \%$. The volume fiber fraction has a major effect on the failure of the interface. In natural fiber-reinforced composites, porous fiber structures contributing to the addition of composite volume as a whole will have an effect on its properties. Natural fibers are able to absorb moisture so that fiber weight can increase to $40 \%$, this depends on the relative humidity [3-7]

Natural fibers are hydrophilic organic polymers tend to be easily to moist, thus negatively affecting mechanical properties. The weak bond between the thermoplastic matrix and the natural fibers results in having low adhesive properties that will affect the overall composite properties. This is due to the presence of hydroxyl groups on the walls of natural fiber cells making them susceptible to moisture [8]. The weakness is the advantage because through the $\mathrm{OH}$-group site can be chemical modification, so it can have dimension of stability and compatibility with thermoplastic matrix Rattan is the group of climbing palms found throughout tropical forests. For centuries people have used them for binding, house construction, and other numerous purposes.
The bonding of polymer composites on rattan fiber is not always good because each of the fiber has different polarity structure, so it is necessary to treat the previous fibers as compatible agent so as to minimize the interfacial tension. Composite of rattan based has replaced petroleum based composites for many applications [9-11] Rattan fibers are often equated with synthetic glass fibers because of its similar of tensile strength which can reaches from 464 to $603 \mathrm{MPa}$ depends on the species,[12] so it is recognized more interesting than steel [13]. Indonesia meets $80 \%$ of the world's rattan needs, $90 \%$ comes from natural forest and $10 \%$ from cultivation [14].

This research has been carried out of using natural fiber; rattan as the reinforcement for matrix. Finding the optimized mechanical property of the composite is the main goals.

\section{Materials and methods}

\subsection{Sample preparation}

The fiber Rattan used in this research are originally grows near the Barito River in Kalimantan island. The common name of the rattan from the locals is Jawit. Usually is used for furniture, the texture is less smooth, very brittle which easily broken even though it has been immersed in water.

Materials

The Jawit rattan fiber was purchased from rattan traders in East Jakarta area. The fiber is cleaned with knife until it reaches 0.2 $\mathrm{cm}$ of thickness. Dimethylethanolamine (DMEA) and Silane A174 product of Merck adhesion are used for for curing promoter.

Methods

According to previous research founding, using rattan fibers for fiber reinforcement will be damaged during the storage as if without alkilation treatment, because the fiber stores high water 
content in certain moisture so it caused to mold formation and which can affect its mechanical properties. The fiber's color tends to change with alkilation treatment at any concentration. For $25 \%$ of alkilation the color turns to maroon red, as the lignin layer on the surface is more loose. This will affect the overall composite strength. Visually the fiber with $25 \%$ alkilation tends to be more fragile after three months observation where the surface was overgrown with mushrooms [15]. In this study we found the best $\mathrm{NaOH}$ concentration for alkilation treatment was $5 \%(\mathrm{v} / \mathrm{v})$ within 10 minutes of immersion. Rattan fibers are tested previously to measure whether are compatible with prepared resins. Selection of Resin blending with its Preliminary Test namely: Synthetic (WS Chem-01), corn oil epoxide with hardener (WS Chem-02).

- Sample 1: (WS Chem-01) + (WS Chem-02)

- Sample 2: (Corn oil Epoxide) + (WS- Chem -02)

- Sample 3: (WS Chem-01) + (corn oil epoxide $)+$

$$
\text { Chem-02) }
$$

Epoxy based resin is a synthetic thermoplastic resin, it was prepared to be applied to rattan fiber which consist of; 1) conducting the initial test using anhydrous maleic acid $\left(\mathrm{C}_{4} \mathrm{H}_{2} \mathrm{O}_{3}\right.$ mass 98.06 $\mathrm{g} / \mathrm{mol}$ of Merck Germany) in crystalline form. Observations can not be included in the reaction because it does not form a homogeneous mixture in distilled water and polyols. A temporary hypothesis is the need for heat treatment or add a compatible agent to the mixture 2) Epoxy based resin were blended with hardener and added Dimethylethanolamine (DMEA) and 3) Epoxy based resin mixed with hardener and added Silane.

\subsection{Rattan Fiber Preparation:}

Rattan fiber is prepared in two dimensions; the dimension for short fiber was $1 \mathrm{~cm} \mathrm{x} 1 \mathrm{cmx} 0.2 \mathrm{~cm}$ and the long fiber was $1 \mathrm{~cm} \mathrm{x}$ $15 \mathrm{~cm} \times 0.2 \mathrm{~cm}$. The Short fibers are prepared as a reference to the alkilation response. The long fibers are woven with the predetermined patterns. Basic pattern selection is to know the strength of composite rattan with different patterns. The rattan fibers are applied for 5\% alkilation treatment. The alkaline ratted fibers are immersed for 10 minutes. Then washed clean with aquadest flowed for 5 minutes until the rattan fiber is free of the alkali compound, it is dried for 36 hours. The rattan fiber are woven in two patterns as seen in figure 1 .

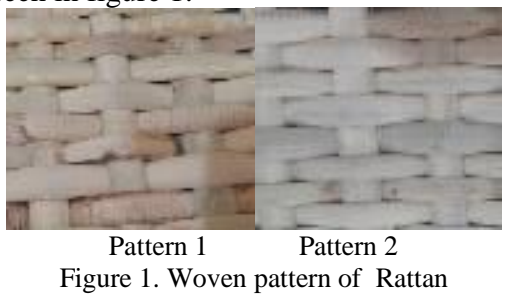

\section{Results and Discussion}

\subsection{Fourir Test of Infra-Red (FTIR)}

The test was done to identify the functional group of blending resin and hardener, executed type of blending resin will be used for the proceed work.

\section{Resin sample 1}

The resin used is blending of (WS Chem-01) with $\mathrm{h}$ hardener (WS Chem-02), the curing time has reaches 14:31 I minute, and the mixture density is $\rho=0.817 \mathrm{gr} / \mathrm{cm}^{3}$.

Aliphatic CH stretching vibration at wavelengths of 2965, 2927, and $2874 \mathrm{~cm}^{-1}$. There are $\mathrm{C}=\mathrm{C}$ aromatics in $1608,1582 \mathrm{~cm}^{-1}, \mathrm{C}$ $=\mathrm{C}$ aromatics at $1509 \mathrm{~cm}^{-1}, \mathrm{CH}_{2}$ and $\mathrm{CH}_{3}$ at $1461 \mathrm{~cm}^{-1}, \mathrm{CH}_{3}$ in $1415, \mathrm{CH}_{3}$ bending at $1383 \mathrm{~cm}^{-1}, \mathrm{CH}_{3}$ symmetrical deformation at $1362 \mathrm{~cm}^{-1}$, CO ester or CO carboxylate at $1292 \mathrm{~cm}^{-1}$, CO stretching at $1246,1184 \mathrm{~cm}^{-1}$, CO stretching or COC at $111 \mathrm{~cm}^{-1}, \mathrm{COC}$ at $1083 \mathrm{~cm}^{-1}$, vibrating stretching symmetric aromatic ether and $\mathrm{CH}$ from 1,4 Benzene substitution at $1035 \mathrm{~cm}^{-1}, \mathrm{CH}=\mathrm{CH}$ or $\mathrm{CH}$
$=\mathrm{CH}_{2}$ or carbon or $\mathrm{COC}$ ring at $907 \mathrm{~cm}^{-1}$, vibrating epoxy group (glycidil Ester) at $914 \mathrm{~cm}^{-1}$, CO epoxide $830 \mathrm{~cm}^{-1} ; 1,2,3$ trisubstituted benzene at $767 \mathrm{~cm}^{-1},\left(\mathrm{CH}_{2}\right)$ at $731 \mathrm{~cm}^{-1}, \mathrm{OC}=\mathrm{O}$ carboxylic acid or CC-CHO aldehyde at $674 \mathrm{~cm}^{-1}, \mathrm{OC}=\mathrm{O}$ carboxylic acid or $\mathrm{C}-\mathrm{CO}-\mathrm{O}$ ketone at $628 \mathrm{~cm}^{-1}$.

\section{Resin Sample 2}

The resin used is blending of corn epoxide + WS- Chem -02 with infinite curing time, and the mixture density is $\rho=0.578 \mathrm{gr} / \mathrm{cm}^{3}$.

There is an aliphatic $\mathrm{CH}$ stretching vibration at wavelengths of 2926, $2855 \mathrm{~cm}^{-1}, \mathrm{C}=\mathrm{O}$ ester at $1743 \mathrm{~cm}^{-1}, \mathrm{C}=\mathrm{O}$ carboxylic acid or $\mathrm{C}=\mathrm{C}$ or $\mathrm{NH}$ at $1646 \mathrm{~cm}^{-1}, \mathrm{NH}$ at $1556 \mathrm{~cm}^{-1}, \mathrm{C}=\mathrm{C}$ aromatic at $1515 \mathrm{~cm}^{-1}, \mathrm{CH}_{2}$ and $\mathrm{CH}_{3}$ at $1462 \mathrm{~cm}^{-1}, \mathrm{CH}_{3}$ bending at $1379 \mathrm{~cm}^{-1}$, stretching $\mathrm{CO}$ at $1159 \mathrm{~cm}^{-1}$, stretching COC or COC at $1107 \mathrm{~cm}^{-1}$, symmetrical vibrations of symmetrical ether and $\mathrm{CH}$ from 1,4 Benzene substitution at $1042 \mathrm{~cm}^{-1}, \mathrm{CH}=\mathrm{CH}$ or $\mathrm{CH}=\mathrm{CH}_{2}$ or carbon or COC ring at $961 \mathrm{~cm}^{-1}$, epoxy ring at $896 \mathrm{~cm}^{-1}$, CO epoxide at $830 \mathrm{~cm}^{-1} ; 1,2,3$ trisubstituted benzene in 781 and $757 \mathrm{~cm}^{-1}$, $\left(\mathrm{CH}_{2}\right)$ at $734 \mathrm{~cm}^{-1}, \mathrm{OC}=\mathrm{O}$ carboxylic acid or $\mathrm{CC}-\mathrm{CHO}$ aldehyde in $672,656 \mathrm{~cm}^{-1}$, CC-CHO aldehyde or OCO ester on $642 \mathrm{~cm}^{-1}$.

\section{Resin Sample 3}

The resin used is blending of WS Chem- $01+$ corn oil epoxide + WS Chem-02 with curing time 14: 46 minute, and the mixture density is $\rho=0.6316 \mathrm{gr} / \mathrm{cm}^{3}$.

There is $\mathrm{OH}$ at $3353 \mathrm{~cm}^{-1}$, aliphatic $\mathrm{CH}$ stretching vibrations at 2925 , and $2854 \mathrm{~cm}^{-1}, \mathrm{C}=\mathrm{O}$ carboxylic acid or $\mathrm{C}=\mathrm{C}$ or $\mathrm{NH}$ at $1640 \mathrm{~cm}^{-1}$ and $\mathrm{C}=\mathrm{C}$ aromatics at $1611 \mathrm{~cm}^{-1}, \mathrm{NH}$ at $1561 \mathrm{~cm}^{-1}, \mathrm{C}$ $=\mathrm{C}$ aromatic $1510 \mathrm{~cm}^{-1}, \mathrm{CH}_{2}$ and $\mathrm{CH}_{3}$ at $1464 \mathrm{~cm}^{-1}, \mathrm{CH}_{3}$ bending at $1381 \mathrm{~cm}^{-1}, \mathrm{CH}_{3}$ symmetrical deformation at $1362 \mathrm{~cm}^{-1}, \mathrm{CO}$ ester or CO carboxylate at $1300 \mathrm{~cm}^{-1}$, Stretching CO at $1183 \mathrm{~cm}^{-1}$, stretching or COC CO at $1113 \mathrm{~cm}^{-1}$, symmetrical vibration aromatic ether and $\mathrm{CH}$ from 1,4 Benzene substitution at $1041 \mathrm{~cm}^{-1}$, $\mathrm{CH}=\mathrm{CH}_{2}$ or $\mathrm{CH}_{2}=\mathrm{C}-\mathrm{R} 2$ at $928 \mathrm{~cm}^{-1}, \mathrm{CO}$ epoxide at $830 \mathrm{~cm}^{-1}$; $1,2,3$ trisubstituted benzene at $769 \mathrm{~cm}^{-1},\left(\mathrm{CH}_{2}\right)$ - at $726 \mathrm{~cm}^{-1}, \mathrm{OC}=$ $\mathrm{O}$ carboxylic acid or CC-CHO aldehyde in 690 and $656 \mathrm{~cm}^{-1}$, OC $=\mathrm{O}$ carboxylic acid or C-CO $-\mathrm{O}$ ketones at $632 \mathrm{~cm}^{-1}$.

The selection of three combination of resin (resin-1, resin-2, and resin-3) we have concluded the edible based epoxy of corn oil were not compatible to synthetic resin because the blending is more fluidized and is hard to solidified to meet its curing time. For the proceed work we have used resin-1.

\subsection{Alkilation to Mass Relative}

Alkilation treatment is a modified surface stage of rattan fiber which has caused the fibers experience relative mass losses, where the small fiber dimensions will lose more than the long fibers. It is marked with fading color to reddish brown in terms of visual the rattan gloss fades. The relation of the treatment to fiber mass relative as illustrated in Figure 2.

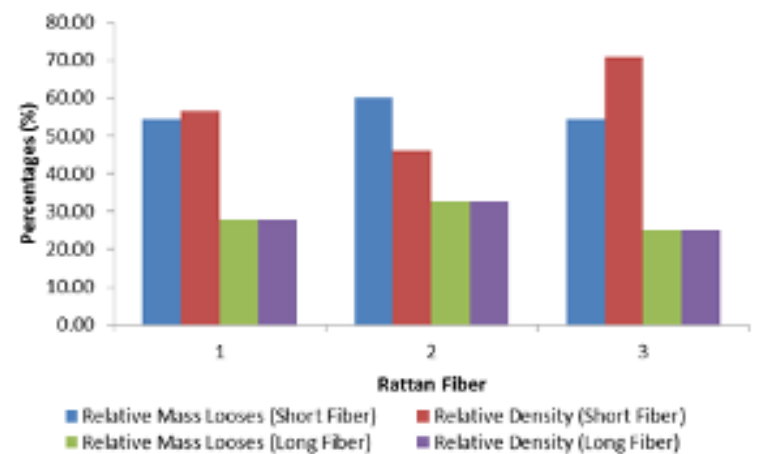

Figure 2. The effect of $5 \%(\mathrm{v} / \mathrm{v})$ alkilation to relative mass looses and relative density of short and long fiber

\subsection{Flexural Test}

Flexural test is often referred to as modulus of rupture or bend strenght, is a mechanical test aimed on knowing the brittleness of material. A composite material coated by a polymer matrix allows 
for a flexible response. The interaction between fiber and adhesives booster produces a composite material of a certain strength. In this study we found composite using silane is in the range of between 3.19 to $10.89(\%, \mathrm{w} / \mathrm{w})$ and the range of using DMEA is 2.79 to $13.10(\%, \mathrm{w} / \mathrm{w})$. The use of DMEA and Silane respectively in blending of epoxy resin + hardener provides significant flexural properties.

The fiber woven pattern provides a certain strength in the composite material in addition to the bonding strength between the matrix and the fibers. The use of DMEA in the flexural in pattern- 1 is $0.86\left(\mathrm{kgf} / \mathrm{mm}^{2}\right)$ and the pattern-2 yields $1.71\left(\mathrm{kgf} / \mathrm{mm}^{2}\right)$ they both are immersed in distilled water for 1 hour. If compared to bending modulus of composite pattern- 1 without water immersion are respectively $1.05\left(\mathrm{kgf} / \mathrm{mm}^{2}\right)$ with DMEA and $1.43(\mathrm{kgf} /$ $\mathrm{mm}^{2}$ ) with silane. The use of Silane if immersed in water using woven pattern- 2 is stronger than the pattern- 1 which are respectively $2.79\left(\mathrm{kgf} / \mathrm{mm}^{2}\right)$ and $1.84\left(\mathrm{kgf} / \mathrm{mm}^{2}\right)$.

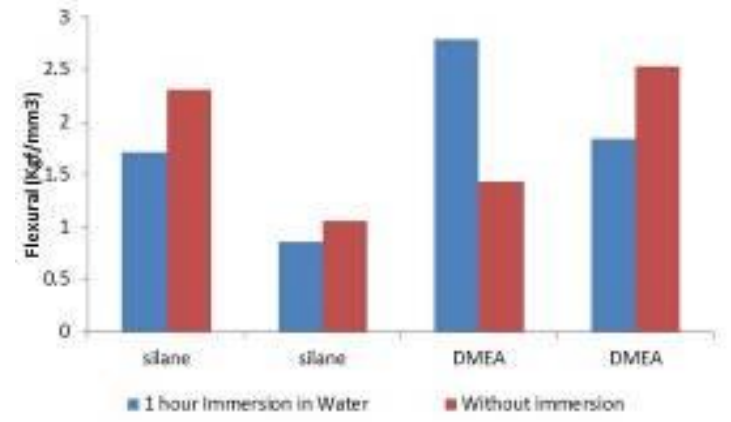

Figure 3. The effect of adhesives booster to flexural

The similar composite with DMEA woven pattern-1 and Silane pattern-1 are immersed in water for 1 hour hence with the result is $1.7\left(\mathrm{kgf} / \mathrm{mm}^{2}\right)$ and $0.86\left(\mathrm{kgf} / \mathrm{mm}^{2}\right)$ with mean $1.28\left(\mathrm{kgf} / \mathrm{mm}^{2}\right)$ in DMEA and $1.84\left(\mathrm{kgf} / \mathrm{mm}^{2}\right)$ in Silane.

In general hypothesis can be made that Silane flexible modulus is stronger in DMEA with woven pattern-1, so as the woven pattern2 the flexible modulus of Silane is higher than DMEA. In the composite using DMEA the woven pattern-2 is stronger than the woven pattern-1, the same happened to woven pattern-2 using Silane where the flexure module is higher than the woven pattern-1. If submersed in water the composite using DMEA has high bending strength compared to Silane without immersion.

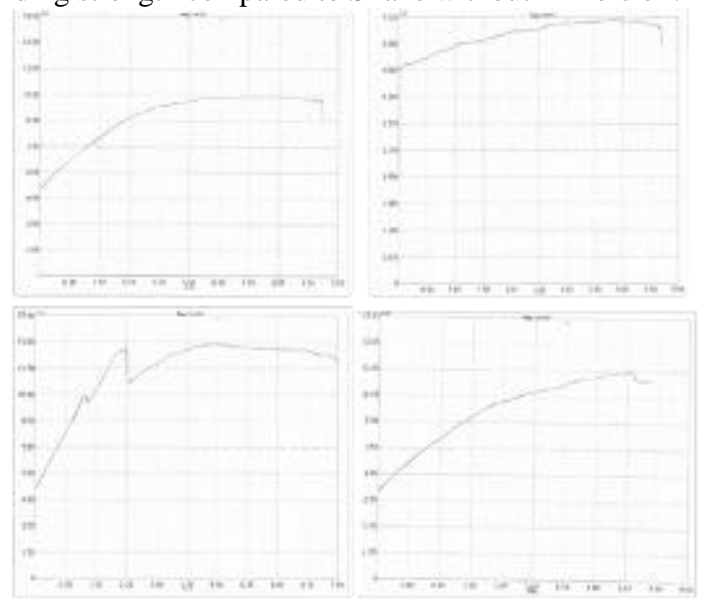

Figure 4. The Effect of Immersion to Composite Flexural strenght

\subsection{Tensile Test and Elongation at Break}

The instrument conditions for tensile tests are as follows: with $50 \%$ humidity, tensile speed $2 \mathrm{~mm} / \mathrm{min}$ and grip spacing is 50 $\mathrm{mm}$. The composite sample to be tested by tensile test is by code; sample A12, A2, B2, B7, and B12. While sample A12 and A2 are composites made from blending resin of epoxy + hardener + silane with pattern-1. While B2 is blending of epoxy resin + hard- ener + DMEA with woven pattern-1 whereas B7 and B12 are DMEA with woven pattern-2. The standard deviation to the 5 samples above is quite small is 0.66681 while the standard deviation width to 5 samples is 4.33196 .

On A2 and A12 are composites using Silane with woven pattern-1. While sample B2, B7, and B12 are composites using DMEA with woven pattern-1 in B2 and pattern-2 in B7 and B12. Visibly the tensile tests using DMEA and silane are not significantly different, the elongation at breaks of using DMEA is more tough than silane. Overall woven pattern-2 is stronger than woven pattern-1.

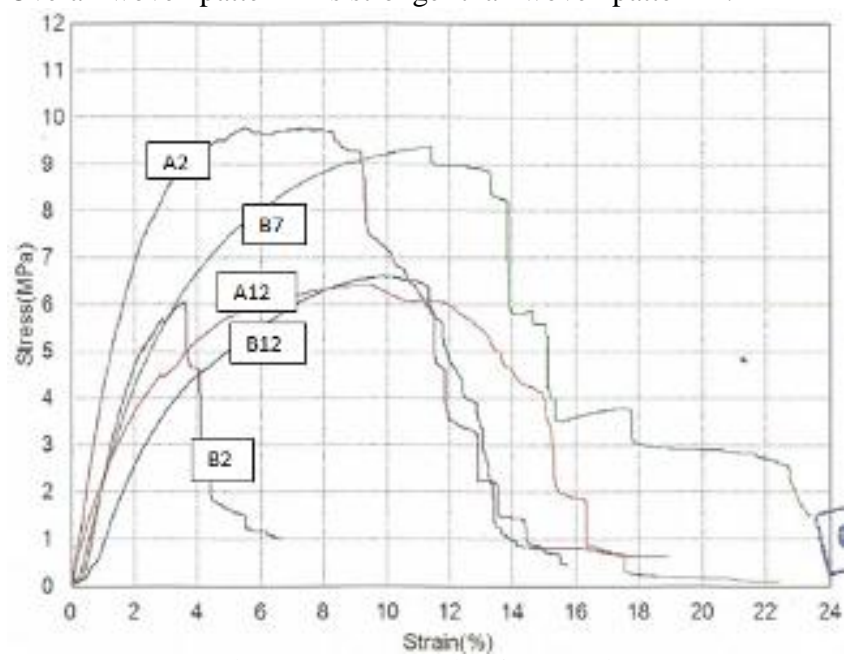

Figure 4. Stress- Strain of Composite

\subsection{Hardness Test}

The composite surface is homogeneous making it possible to carry out hardness tests. The hardness test of composite material is not significantly different with standard deviation of 0.5 . The designated composite tested are silane, which to compare woven pattern-1 sample \#A1 to woven pattern-2 as can be seen in Table 1.

Table 1. Hardness Test

\begin{tabular}{|c|c|c|}
\hline No & Specimen & Hardness Shore D \\
\hline 1 & A1 & 52 \\
\hline 2 & A7 & 51 \\
\hline 3 & A8 & 51 \\
\hline 4 & A9 & 52 \\
\hline 5 & A10 & 51 \\
\hline & Mean & 51.4 \\
\hline \hline
\end{tabular}

\subsection{Thermal Test}

Glass Temperature and melting temperature of polymer matrix is resulted observations of 5 samples are performed using silane as where the glass temperature $(\mathrm{Tg}) \mathrm{A} 5=63.39{ }^{\circ} \mathrm{C}$ and $\mathrm{Tg} \mathrm{A} 15=$ $64.39{ }^{0} \mathrm{C}$.

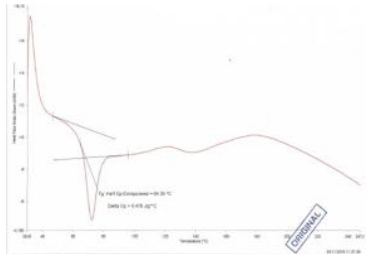

Silane with woven pattern-2

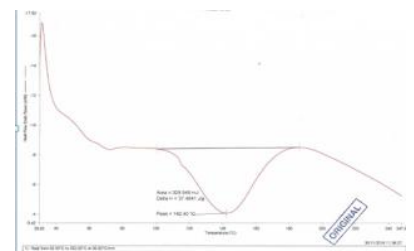

DMEA with woven pattern-1
Figure 5. DSC test using DMEA and silane

The samples using DMEA are sample B5, B10 and B5 which are respectively $\mathrm{B} 5 \mathrm{Tm}=142.40{ }^{\circ} \mathrm{C}, \mathrm{B} 10 \mathrm{Tm}=145.74^{\circ} \mathrm{C}$, and $\mathrm{B} 15$ $\mathrm{Tm}=146.94^{\circ} \mathrm{C}$.

From these observations it is known that the composite uses Silane produced an amorph polymer because the sample does not 
produce melting temperature while using DMEA is produced crystalline polymer.

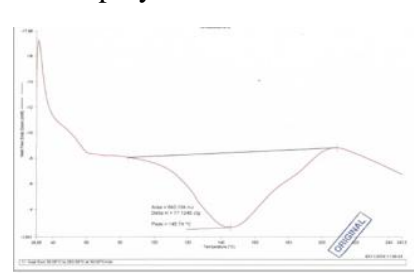

DMEA with woven pattern-1 previously immersed in distilled water

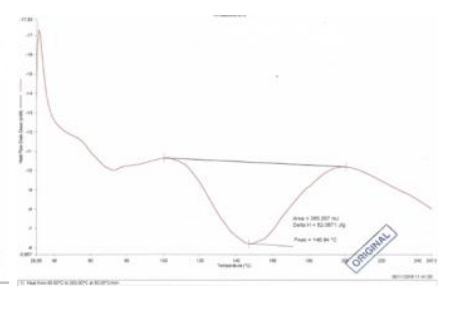

DMEA with woven pattern-2

Figure 6. DSC test using Silane to pattern-1 and pattern 2

\section{Conclusion}

The result of has concluded the flexural test of rattan-made composite must include soaking in water in production process before applying resin + silane, because this treatment opened surfaces pore which has made enhancing the interaction of matrix and adhesive booster to rattan fiber. The DMEA does not need to be immersed in water. It is recommended to be made more crossed woven patterns to yield stronger composite.

\section{Acknowledgement}

The author is gratefully acknowledge the support of the Ministry of Research and Technology and Higher Education of the Republic of Indonesia as funding the research in the scheme of National Competency Grant.

\section{References}

[1] Mathew, et. al, Mechanical properties of biodegradable composites from poly lactic acid (PLA) and microcrystalline cellulose, J. Appl. Polym., Sci; 97, 2014-2025, 2005

[2] Bo Madsen, Properties of plant fiber yarn polymer composites: an experimental study, BYGDTU R-082, ISSN 1601-2917, ISBN $87-$ pp.7877-145-5, 2004

[3]Goutianosa, B. Peijsb, B. Nystromc, M. Skrifvardsd, Textile reinforcements based on aligned flax fibers for structural composites, Project (TEXFLAX), Funded by European Union (Growth Project No: G5ST-CT-2001-50111). http://www.risoe. dk/rispubl/art/2007_245_paper.pdf, 2007

[4]H. Bryan, Engineering composite materials, The Institute of Materials, London, 1999

[5]Ning. Pan, Theoretical determination of the optimal fiber volume fraction and fiber matrix property compatibility of short fiber composites, Polymer Composites 14 (2), pp. 85-93, 1993

[6] T.Wasik, Effect of fiber volume fraction on fracture mechanics in continuosly reinforced fiber composite materials, $\mathrm{Ph}$.D. Theses, University of South Florida, 2005

[7] M. Zimniewska, M. Radwanski, Natural fibers yarns suitable for composites, http://www.Eucia.org/Files/Yarns.pdf.

[8] Spiridon J., Natural Fiber - Polyolefin Composites. Mini-Review, Cellulose Chem. Technology, 48 (7-8), pp.599-612, 2014

[9] Krishnaparasad et.al., Mechanical and thermal properties of bamboo microfibril reinforced polyhydroxybutyrate biocomposites, $\mathbf{J}$ Polym Environ, 17: doi 10.1007/s10924-009-0127-x, pp. 1091142009

[10] Han et.al., Bamboo-fiber filled high density polyethylene composites: Effect of coupling treatment and nanoclay, J Polym Environ, doi 10.1007/s10924-008-0094-7, 2008

[11] Chung, K.F and W.K. Yu, Mechanical properties of structural bamboo for bamboo scaffoldings, Engineering structures, 24: pp.429442, 2002

[12] Xing'e Liu, Rui Wang, Genlin Tian, Shumin Yang, Youhong Wang, Zehui Jiang, Tensile Properties of Single Rattan Fibers, Wood and Fiber Science, Vol 46, No 4 (2014)

[13] Thwe, MM and Liao, Environmental effetcs on bambooglass/polypropylene hybrid composites, Journal of materials science letters, 19: pp. 1873-1876, 2003

[14] https://unhas.ac.id/fahutan/index.php/id/buku-ajar
[15] FE Firdaus, An Environmental Friendly Material: Epoxide Based Resin from Vegetables Oil for Bio- Fiber Reinfoced Composite, International Journal of Applied Engineering Research, vol 11, No 7, pp. $5152-5155,2016$. 